\title{
Heterogeneous electron transfer kinetics and electrocatalytic behaviour of mixed self-assembled ferrocenes and SWCNT layers
}

\author{
Duduzile Nkosi, ${ }^{a}$ Jeseelan Pillay, ${ }^{a}$ Kenneth I. Ozoemena, ${ }^{* a b}$ Khalid Nouneh ${ }^{c d}$ and \\ Munetaka Oyama ${ }^{c}$
}

Received 9th September 2009, Accepted 20th October 2009

First published as an Advance Article on the web 16th November 2009

DOI: $10.1039 / b 918754 \mathrm{e}$

\begin{abstract}
The electron transfer dynamics and electrocatalytic behaviour of ferrocene-terminated self-assembled monolayers (SAMs), co-adsorbed with single-walled carbon nanotubes (SWCNTs) on a gold electrode, have been interrogated for the first time. Ferrocene monocarboxylic acid (FMCA) or ferrocene dicarboxylic acid (FDCA) was covalently attached to the cysteamine (Cys) monolayer to form Au-Cys-FMCA and Au-Cys-FDCA, respectively. The same covalent attachment strategy was used to form the mixed SWCNTs and ferrocene-terminated layers (i.e. Au-Cys-SWCNT/FMCA and Au-Cys-SWCNT/FDCA). Using cyclic voltammetry and electrochemical impedance spectroscopy, the impact of neighbouring SWCNTs on the electron transfer dynamics of the ferrocene molecular assemblies in an acidic medium $\left(0.5 \mathrm{M} \mathrm{H}_{2} \mathrm{SO}_{4}\right)$ and in a solution of an outer-sphere redox probe $\left(\left[\mathrm{Fe}(\mathrm{CN})_{6}\right]^{4-} /\left[\mathrm{Fe}(\mathrm{CN})_{6}\right]^{3-}\right)$ was explored. The electron transfer rate constants in both media essentially decreased as Au-Cys-FMCA > Au-Cys-SWCNT/FDCA > Au-Cys-FDCA > Au-Cys-SWCNT/FMCA. This trend has been interpreted in terms of several factors such as the locations of the ferrocene species in a range of environments with a range of potentials, the proximity/interactions of the ferrocenes with one another, and electrostatic interaction or repulsion existing between the negatively-charged redox probe and the modified electrodes. The thiocyanate ion $\left(\mathrm{SCN}^{-}\right)$was used as a model analyte to examine the influence of the neighbouring SWCNTs on the electrocatalytic ability of the ferrocene assemblies. The Au-Cys-SWCNT/FDCA showed the best catalytic activity (in terms of onset potential and catalytic peak current height) for the oxidation of $\mathrm{SCN}^{-}$, possibly due to the repulsive interactions between the negatively charged $\mathrm{SCN}^{-}$and high number of surface $-\mathrm{COOH}$ species at the SWCNT/FDCA. This study has provided some useful insights as to how CNTs co-assembled with ferrocene-terminated thiols could impact on the electron transfer kinetics as well as the electrocatalytic detection of the self-assembled ferrocene layers.
\end{abstract}

\section{Introduction}

Ferrocene $(\mathrm{Fc})$ and its derivatives are well known electrocatalysts. One of the interesting techniques of immobilising them onto electrode surface is by self-assembly. Self-assembly simply describes the science of things that put themselves together. ${ }^{1}$ A self-assembled monolayer (SAM) has been described as an ideal system for disentangling the fundamental events in interfacial electron transfer. ${ }^{2}$ Several reports have established that the redox kinetics of self-assembled monolayers of ferrocenes are influenced by other molecules that share the same local microenvironments with them. For example, Weber et al. ${ }^{3}$ reported that electron transfer (ET) is dependent on the chain length of the mercapto-alkanol to

${ }^{a}$ Department of Chemistry, University of Pretoria, South Africa

${ }^{b}$ Energy \& Processes Unit, Materials Science and Manufacturing, Council for Scientific and Industrial Research (CSIR),

Pretoria 0001, South Africa.E-mail: kozoemena@csir.co.za;

Fax: + 27 (0)12841 2135; Tel: + 27 (0)128413664

${ }^{c}$ Department of Material Chemistry, Graduate School of Engineering, Kyoto University, Nishikyo-ku, Kyoto 615-8520, Japan

${ }^{d}$ The Institute of Nanomaterials and Nanotechnology (INanotech), Rabat, Morocco which the Fc is attached. Sumner and Creager ${ }^{4}$ showed that the electron transport of Fc SAM is related to the extent to which alkanethiols permit the exposure of the $\mathrm{Fc}$ on to the electrolyte. Recently, Hortholary and Crouchet ${ }^{5}$ showed that an $\mathrm{Ru}$ complex co-assembled with $\mathrm{Fc}$ on gold exerts some influence on the heterogeneous electron transfer (HET) of the Fc. In addition, several workers have also shown that thiol adsorbates containing ferrocene head groups are important for interrogating the chemical features of monolayers on gold substrates. For example, Collman et al. ${ }^{6}$ used ferrocene adsorption to demonstrate the applicability of Sharpless "click" chemistry as a general methodology for functionalizing surfaces coated with self-assembled monolayers. Chidsey and co-workers ${ }^{2}$ studied co-adsorbed ferrocene and unsubstituted alkanethiol and observed the structural orientation/changes that accompany concentration changes; Aluletta et al. ${ }^{7}$ studied mixed SAMs of ferrocene-terminated thiols and hydroxyalkanethiols and proved the occurrence of phase separations; Ye et al. ${ }^{8}$ observed coverage-dependent behavior of the ferroceneterminated thiol SAMs induced by the redox reaction of the terminal ferrocene moiety, while Waldeck and co-workers ${ }^{9}$ studied ferrocene co-assembled with alkanethiolate SAMs and 
showed how intermolecular electronic coupling pathways could contribute to the electron transfer; Uosaki and co-workers ${ }^{10}$ studied SAM containing both ferrocene and azobenzene moieties and established how electro- and photochemical structural conversion of the cis and trans forms of the azobenzene moiety could impact on the charge-transfer processes; Crooks and co-workers ${ }^{11}$ studied mixed monolayers of ferrocene-dendrimers and alkanethiols and, for the first time, introduced an elegant strategy for constructing an electrochemical current rectifier that permits current flow in only one direction; and Chambers et al. ${ }^{12}$ reported how a ferrocene-thiol SAM co-adsorbed with alkanethiolates could unravel nanoscale phase separation.

To our knowledge, there is no report on ferroceneterminated SAMs co-adsorbed with CNTs. Hence, until now, it was not known how CNTs co-assembled with ferroceneterminated thiols could impact on the electrochemistry of ferrocene moiety. The only known reports on CNTs are those where Fcs were covalently attached onto the ends of CNT SAMs via amide ${ }^{13,14}$ or ester ${ }^{15}$ bonds. This somewhat surprising considering that CNTs could enhance intermolecular electron transfer between ferrocene sites by behaving as electronic bridges. To address this discrepancy, we show for the first time, the electrochemistry of mixed SAMs of single-walled carbon nanotubes (SWCNTs) and Fcs and examined the influence of SWCNTs on the HET of immobilized Fcs and electrocatalytic detection of a thiocyanate as an analytical probe. Thiocyanate is well known for its environmental and clinical importance. ${ }^{16-18}$ We show that CNTs have distinct influence on the HET and electrocatalytic properties of these self-assembled Fc complexes. In summary, this study is crucial as it could provide some useful physical insights into the impact of local microenvironment surrounding a redox-active molecule (not only ferrocene but other organometallic species) on the dynamics of charge transport between a redox molecule and electrode. Such insights will create some knowledge on the factors that must be considered when designing CNT-based molecular-scale electronics or electrocatalytic devices that transport charges within organized molecular assemblies in such a manner as to accomplish specific functions.

\section{Experimental}

\subsection{Materials and methods}

Ferrocenemonocarboxylic acid (FMCA) was from Fluka. Ferrocenedicarboxylic acid (FDCA), cysteamine hydrochloride (Cys), dicyclohexylcarbodiimide (DCC) and single-walled carbon nanotubes (SWCNTs) and $N, N$-dimethylformamide (DMF) were obtained from Sigma-Aldrich. The pristine SWCNTs were acid-functionalized as previously reported. ${ }^{19,20}$ Ultra pure water of resistivity $18.2 \mathrm{M} \Omega \mathrm{cm}$ from a Milli-Q Water System (Millipore Corp., Bedford, MA, USA) was used throughout for the preparation of solutions. Phosphate buffered solutions (PBS) was prepared with $\mathrm{NaH}_{2} \mathrm{PO}_{4} \cdot \mathrm{H}_{2} \mathrm{O}$. All other reagents were of analytical grades and were used as received from the suppliers without further purification.

AFM images were acquired with AFM 5100 System (Agilent Technologies, USA) using AC mode AFM scanner interfaced with a PicoScan 5.0 controller. Silicon type PPP-NCH-20 (Nanosensors ${ }^{\circledR}$ ) of thickness $4.0 \pm 1.0 \mu \mathrm{m}$, length $125 \pm 10 \mu \mathrm{m}$, width $30 \pm 7.5 \mu \mathrm{m}$, spring constants $10-130 \mathrm{~N} \mathrm{~m}^{-1}$, resonant frequencies of $204-497 \mathrm{kHz}$ and tip height of $10-15 \mu \mathrm{m}$ were used. All images were taken in air at room temperature.

Electrochemical experiments were carried out using an Autolab Potentiostat PGSTAT 302 (Eco Chemie, Utrecht, The Netherlands) driven by the General Purpose Electrochemical Systems data processing software (GPES, software version 4.9). Electrochemical impedance spectroscopy (EIS) measurements were carried out with an Autolab FRA software between $0.1 \mathrm{~Hz}$ and $10 \mathrm{kHz}$ using a $5 \mathrm{mV}$ rms sinusoidal modulation. The FRA software allowed the fitting of the raw EIS data to equivalent circuit models using a complex non-linear least squares (CNLS) routine, with Kramers-Kronig rule check. The working electrode was bare gold $(r=0.8 \mathrm{~mm}$, BAS) or the same gold electrode modified with the investigated SAMs. An $\mathrm{Ag} \mid \mathrm{AgCl}$ wire and platinum wire were used as pseudo-reference and counter electrodes, respectively. As in a previous report, ${ }^{21}$ we used the reversible electrochemistry of $\left[\mathrm{Fe}(\mathrm{CN})_{6}\right]^{3-} /{ }^{4-}$, assuming a diffusion coefficient of $\approx 6.3 \times$ $10^{-6} \mathrm{~cm}^{2} \mathrm{~s}^{-1}, 22$ at scan rates ranging from 10 to $200 \mathrm{mV} \mathrm{s}{ }^{-1}$ and employing the Randles-Sevčik theory, ${ }^{23}$ to estimate the electrochemical roughness factor of the gold electrode (i.e. ratio of the real $\left(0.027 \mathrm{~cm}^{2}\right)$ to geometrical $\left(0.020 \mathrm{~cm}^{2}\right)$ areas) and found it to be $c a$. 1.35. Silver/silver chloride coated with a porous layer of $\mathrm{KCl}$ and platinum were used as reference and counter electrodes, respectively. Prior to modification, the bare Au was first cleaned by first polishing in an aqueous slurry of alumina $(<10 \mu \mathrm{m})$ on a SiC-emery paper (type 2400 grit), and then to a mirror finish on a Buehler felt pad. The electrode was then subjected to ultrasonic vibration in absolute ethanol to remove residual alumina particles that might be trapped at the surface. Finally the electrode was etched for about $2 \mathrm{~min}$ in a hot 'piranha' solution $\left(1: 3(\mathrm{v} / \mathrm{v}) 30 \% \mathrm{H}_{2} \mathrm{O}_{2}\right.$ and concentrated $\left.\mathrm{H}_{2} \mathrm{SO}_{4}\right)$ and then rinsed with copious amounts of ultrapure Millipore water followed by ethanol. (CAUTION: Piranha solution must be handled with care as it reacts violently with organic materials and can explode when stored in closed containers.) This stage was necessary to remove organic contaminants. The cleanliness of the bare electrode surface was finally established by placing it in $0.5 \mathrm{M} \mathrm{H}_{2} \mathrm{SO}_{4}$ and scanning the potential between -0.5 and $1.5 \mathrm{~V}$ (vs. $\mathrm{Ag} \mid \mathrm{AgCl}$ wire) at a scan rate of $0.05 \mathrm{Vs}^{-1}$ until a reproducible scan was obtained. After this check, the electrode was again rinsed with absolute ethanol and immediately placed into a nitrogen-saturated absolute ethanol solution of Cys $(50 \mathrm{mg} / 120 \mathrm{ml})$ for $18 \mathrm{~h}$ at ambient temperature to form the Au-Cys.

\subsection{Modification by sequential self-assembly on gold surface}

Self-assembled monolayers of alkanethiol capped with carboxylated ferrocene and single-walled carbon nanotubes were prepared on gold surfaces. The gold electrode modified with cysteamine is represented as Au-Cys. The formation of Au-Cys-FDCA and Au-Cys-FMCA followed after placing the Au-Cys electrode in a $1 \mathrm{~mL}$ DMF solution containing FDCA 
( $1 \mathrm{mg}, c a .4 \mu \mathrm{mol})$ or FMCA (1 mg, ca. $4 \mu \mathrm{mol})$ and $0.5 \mathrm{mg}$ DCC $(2.4 \mu \mathrm{mol})$ for $48 \mathrm{~h}$, respectively. The Au-Cys-SWCNT/ FDCA electrode was obtained by placing Au-Cys in $1 \mathrm{~mL}$ DMF solution containing a mixture of SWCNT $(\sim 1 \mathrm{mg})$ and FDCA ( $1 \mathrm{mg}, c a .4 \mu \mathrm{mol})$ and $0.5 \mathrm{mg}(2.4 \mu \mathrm{mol})$ DCC for $48 \mathrm{~h}$. This same method was used to prepare Au-Cys-SWCNT/ FMCA, using a mixture of $\sim 1 \mathrm{mg}$ each of SWCNT and FMCA dissolved in $1 \mathrm{~mL}$ DMF. This ratio is adopted throughout the study since it produced the best electrochemistry of the SAMs. Upon removal from the deposition solution, prior to electrochemical experiments, the electrode was thoroughly rinsed with millipore water and dried in a nitrogen atmosphere. The modified electrode was conditioned by placing in $0.5 \mathrm{M} \mathrm{H}_{2} \mathrm{SO}_{4}$ and repetitively scanned between -0.5 and $0.6 \mathrm{~V}$ (vs. $\mathrm{Ag} \mid \mathrm{AgCl})$ potential window at a scan rate of $25 \mathrm{mV} \mathrm{s}^{-1}$ until a constant scan was obtained.

\section{Results and discussion}

\subsection{Electrode fabrication and AFM characterization}

Scheme 1 summarizes the self-assembly process of the FMCA and FDCA onto the gold electrode using cysteamine as the base monolayer. Scheme 2, on the other hand, is a summary of the co-assembling of the SWCNTs and FMCA or FDCA. Both processes (Schemes 1 and 2) employed the normal carbodiimide coupling chemistry, ${ }^{20,24}$ whereby the $-\mathrm{COOH}$ functional groups are first activated to permit the covalent bonding with the $-\mathrm{NH}_{2}$ group of the cysteamine. Confirmation of the attachment of these redox-active species (FMCA, FDCA and SWCNTs) by sequential self-assembly technique was achieved, first, by the use of atomic force microscopy.

Fig. 1 is a comparison of the AFM images of (a) bare Au, (b) Au-Cys-SWCNT, (c) Au-Cys-FDCA and (d) Au-CysSWCNT/FDCA. The needle-like protrusion of the Au-CysSWCNT agrees with several reports for SWCNT-based SAMs. ${ }^{20,25-27}$ Typical lengths of acid-treated SWCNTs using the conditions used in this work lie in the $250-350 \mathrm{~nm}$ range. ${ }^{14}$ However, when we immobilized them as SAMs, the heights lie in the $30-50 \mathrm{~nm}$ range, which is in close agreement with literature. ${ }^{20,25}$ The SWCNTs assembled as bundles and not as individual tubes due to the strong van der Waals attractive forces existing between carbon nanotubes. The same explanation may be true for the needle-like protrusion shown by the Au-Cys-FDCA. Interestingly, as would be expected, the mixed layers, Au-Cys-SWCNT/FDCA, showed more compactness than either the individual layers. Generally, the AFM topographic height and roughness in Fig. 1 are greater with the combined SWCNT and Fc assemblies, exemplified with Au-Cys-SWCNT/ FDCA (d). The roughness and height of the Au-Cys-SWCNT (b) are higher than those of the Au-Cys-FDCA (c) or Au-CysFMCA (not shown), confirming that SWCNTs are longer than the $\mathrm{Fc}$ assemblies (as indicated in the cartoon of Scheme 2).

\subsection{Heterogeneous electron transfer dynamics in $0.5 \mathrm{M} \mathrm{H}_{2} \mathrm{SO}_{4}$ solution}

The cyclic voltammetric properties of the ferrocene-modified gold electrodes were studied in $0.5 \mathrm{M} \mathrm{H}_{2} \mathrm{SO}_{4}$ solution. Fig. 2 shows the $\mathrm{CV}$ profiles of the electrodes obtained at $25 \mathrm{~m} \mathrm{Vs}^{-1}$.

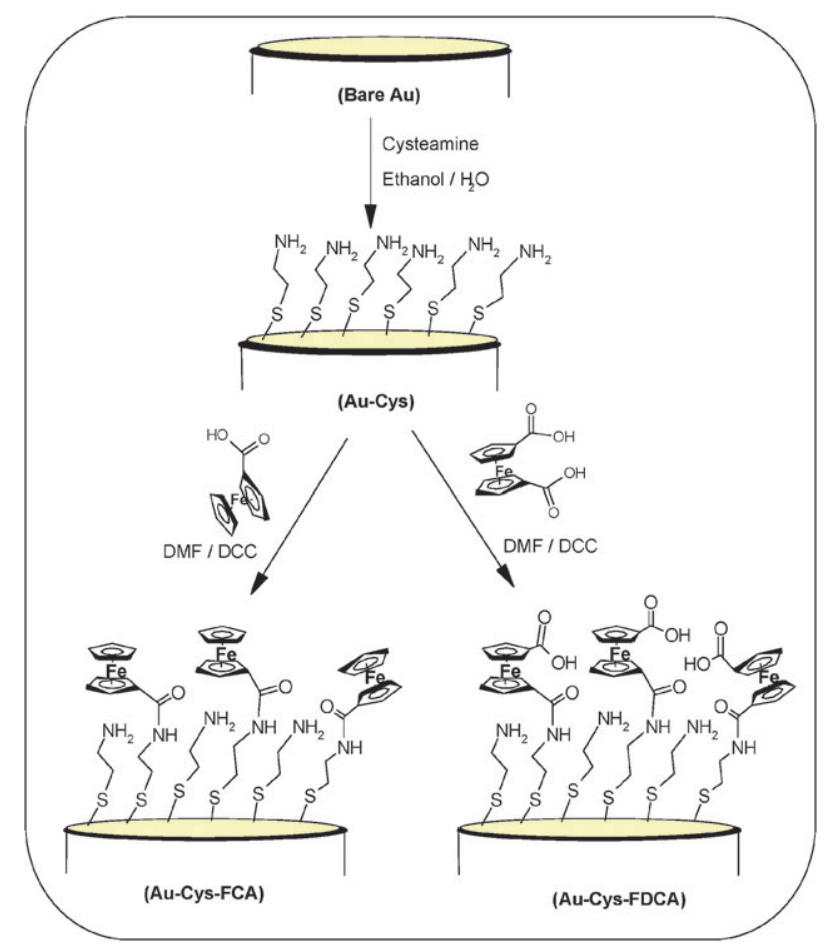

Scheme 1 Schematic of the gold electrode modification routes for Au-Cys, Au-Cys-FCA and Au-Cys-FDCA.

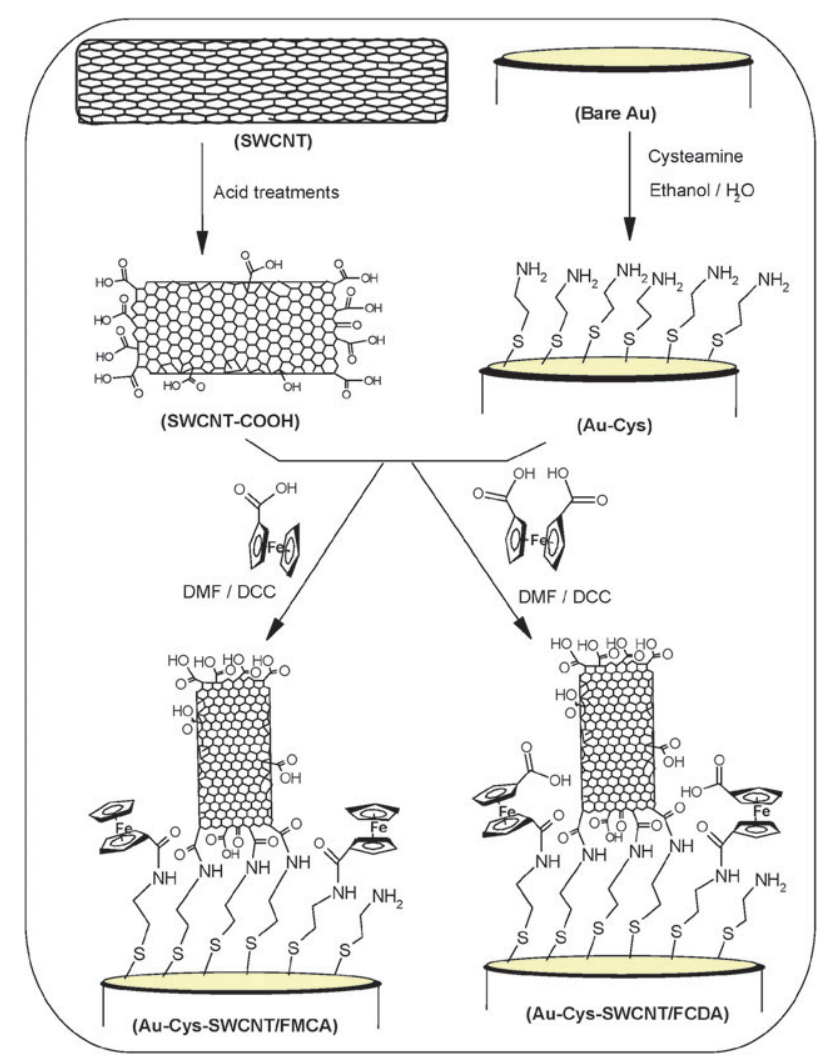

Scheme 2 Schematic of the gold electrode modification routes for Au-Cys-SWCNT/FMCA and Au-Cys-SWCNT/FDCA.

Each of the redox couples is ascribed to the $\mathrm{Fe}(\mathrm{III}) / \mathrm{Fe}(\mathrm{II})$ redox process. The electrochemical parameters, formal potential 


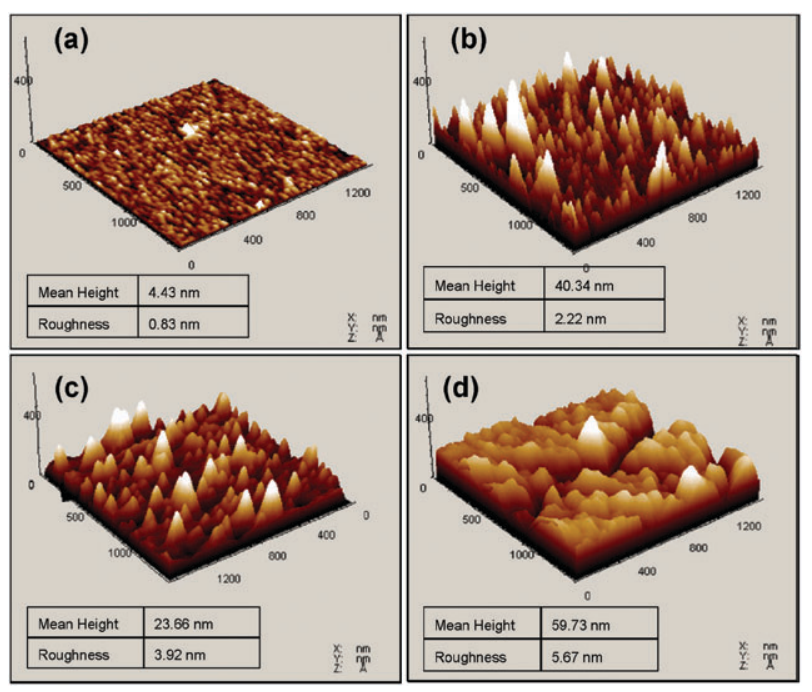

Fig. 1 Typical topographic images of the electrodes: (a) Au bare, (b) Au-Cys-SWCNT, (c) Au-Cys-FDCA and (d) Au-Cys-SWCNT/ FDCA.

$\left(E_{1 / 2} / \mathrm{mV}\right)$, peak-to-peak potential separation $\left(\Delta E_{\mathrm{p}} / \mathrm{mV}\right)$, the width at half the peak current $\left(E_{\mathrm{fwhm}} / \mathrm{mV}\right)$ and ratio of anodic peak current to the cathodic peak $\left(I_{\mathrm{pa}} / I_{\mathrm{pc}}\right)$ and surface coverages $\left(\Gamma / \mathrm{mol} \mathrm{cm}{ }^{-2}\right)$ are summarized in Table 1. All the electrodes show $I_{\mathrm{pa}} / I_{\mathrm{pc}} \approx 1$, indicating voltammetric reversibility. The choice of the potential used here was based on our experience working with thiolated SAMs. As we cautioned in previous reports on SAMs, ${ }^{28,29}$ the thiol monolayer only show remarkable stability in acidic and slightly alkaline $\mathrm{pH}(\mathrm{pH} 2-9)$ at potential between window of -0.5 and $+0.9 \mathrm{~V} v s$. $\mathrm{Ag} / \mathrm{AgCl}$. At more positive potential $(\geq+0.9 \mathrm{~V}$ vs. $\mathrm{Ag} \mid \mathrm{AgCl})$ thiol desorption and/or Au surface oxidation could be observed. The stability observed for these SAMs may be related to some extent by hydrogen bonds arising from the $-\mathrm{COOH}$ and $-\mathrm{OH}$ functional groups. It may also be related to the protection of the sulfur by the large SWCNTs and and/or Fc rings. The interchain attractive interactions resulting from the alkyl chains may also be another contributing factor.

As seen from Table 1, the electron transport (signified by the magnitude $\Delta E_{\mathrm{p}}$ ) in this acid electrolyte condition is fastest at the Au-Cys-SWCNT/FDCA $\approx$ Au-Cys-FMCA and slowest at the Au-Cys-SWCNT/FMCA. In a similar manner, the $E_{\text {fwhm }}$ values (in the $71-117 \mathrm{mV}$ range) slightly deviate from the ideal value of $90.6 / n \mathrm{mV}$ for $n=1,{ }^{30-32}$ with the Au-CysSWCNT/FMCA $(117 \mathrm{mV})$ being slightly greater than that of the Au-Cys-SWCNT/FDCA (104 mV). The higher values of $\Delta E_{\mathrm{p}}$ and $E_{\mathrm{fwhm}}$ for the SWCNT/FMCA compared to its SWCNT/FDCA counterpart may be related to different factors. First, some workers ${ }^{13-15,33}$ have attributed this phenomenon to ferrocene species being located in a range of environments with a range of $E_{1 / 2}$. This should not be totally surprising if one considers the distribution of lengths of the SWCNTs on the gold substrate, and that the ferrocenes studied in this work could possibly be attached to the ends and/or defect sites of the SWCNTs via ester bonds (i.e. between the $-\mathrm{COOH}$ of the

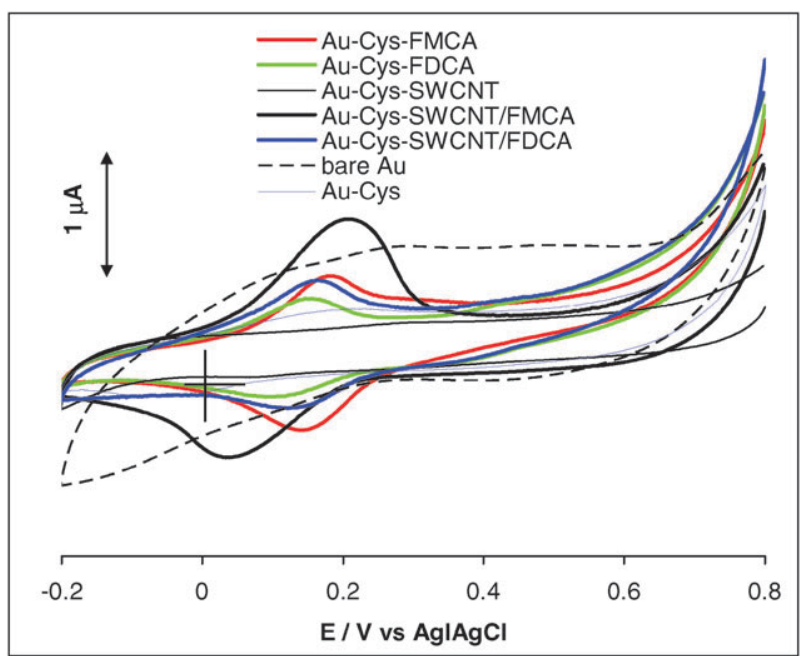

Fig. 2 Comparative cyclic voltammetric evolutions of the modified gold electrode in $0.5 \mathrm{M} \mathrm{H}_{2} \mathrm{SO}_{4}$, Au-Cys-FCA, Au-Cys-FDCA, Au-Cys-SWCNT, Au-Cys-SWCNT/FMCA and Au-Cys-SWCNT/ FDCA. Scan rate $=25 \mathrm{mV} \mathrm{s}^{-1}$.

ferrocene and the few - OH groups on the SWCNTs). By different environments, it is meant that the ferrocene species have different formal potentials, and thus the effective voltammetric wave will consist of a superposition of distinct electrochemical responses, resulting in the observed voltammetric broadening. ${ }^{14}$ It is worth pointing out that the formal redox potentials of the two Fc species will be different. Also, as can be clearly seen from the the CVs, especially in the $0.3-0.8 \mathrm{~V}$ region, the background current or capacitance of the bare $\mathrm{Au}$ $\left(C_{\mathrm{Au}}\right)$ is about three times higher than the capacitance of any of the SAM-modified gold electrode $\left(C_{\mathrm{Au}-\mathrm{SAM}}\right)$. This is expected since in aqueous solution, unlike in organic solutions, the overall electrode double-layer capacitance should be governed by the bare $\mathrm{Au}$ (i.e. $C_{\mathrm{Au}}>\mathrm{C}_{\mathrm{Au}-\mathrm{SAM}}$ ). ${ }^{34,35}$

The second explanation for the non-ideal $\Delta E_{\mathrm{p}}$ and $E_{\mathrm{fwhm}}$ values for the adsorbed ferrocenes may be found from the works of Chidsey and co-workers. ${ }^{2,36,37}$ According to these workers, when the self-assembled ferrocene species are well separated and do not interact with one another, a narrow symmetric redox peak with ideal $E_{\text {fwhm }}$ value of $90.6 / n \mathrm{mV}$ will be obtained. However, as the concentration of the ferrocene adsorbates increases, the resulting voltammograms will become asymmetric, broadening, with an increase in the $\Delta E_{\mathrm{p}}$ value.

The surface coverages were established from the $\mathrm{CV}$ profiles in $0.5 \mathrm{M} \mathrm{H}_{2} \mathrm{SO}_{4}$ using the relationship:

$$
\Gamma=\frac{Q}{n F A}
$$

where $Q$ is the background-corrected charge under the cathodic or anodic waves, $n=$ number of electrons involved in the redox process, $F$ is the Faraday constant, and $A$ is the area of the electrode. The surface coverage values are listed in Table 1. The average coverage increases as follows: SWCNT/FMCA $\left(3.3 \times 10^{-9} \mathrm{~mol} \mathrm{~cm}{ }^{-2}, 2.0 \times 10^{15}\right.$ molecules $\left.\mathrm{cm}^{-2}\right)>$ Cys-FMCA $\left(1.6 \times 10^{-9} \mathrm{~mol} \mathrm{~cm}^{-2}\right.$, 
Table 1 Summary of estimated voltammetric data obtained for the modified electrodes in $0.5 \mathrm{M} \mathrm{H}_{2} \mathrm{SO}_{4}(n=4)$

\begin{tabular}{llrrrr}
\hline & \multicolumn{2}{l}{ Electrochemical parameters } & & \\
\cline { 2 - 6 } Electrodes & $E_{1 / 2} / \mathrm{mV}$ & $\Delta E_{\mathrm{p}} / \mathrm{mV}$ & $E_{\mathrm{fwhm}} / \mathrm{mV}$ & $I_{\mathrm{pa}} / I_{\mathrm{pc}}$ & $10^{9} \Gamma_{\mathrm{a}} / \mathrm{mol} \mathrm{cm}^{-2}$ \\
\hline Au-Cys-FMCA & $158 \pm 2$ & $4.8 \pm 0.4$ & $71 \pm 3$ & 0.8 & $1.6 \pm 0.3$ \\
Au-Cys-FDCA & $131 \pm 3$ & $14.7 \pm 0.9$ & $104 \pm 2$ & 0.9 & $1.1 \pm 0.2$ \\
Au-Cys-SWCNT/FMCA & $137 \pm 2$ & $95.2 \pm 2.8$ & $117 \pm 5$ & 1.1 & $3.3 \pm 0.7$ \\
Au-Cys-SWCNT/FDCA & $146 \pm 4$ & $4.7 \pm 0.6$ & $107 \pm 3$ & 1.1 & $1.4 \pm 0.3$ \\
\hline
\end{tabular}

$9.6 \times 10^{14}$ molecules $\left.\mathrm{cm}^{-2}\right)>\operatorname{SWCNT} /$ FDCA $(1.4 \times$ $10^{-9} \mathrm{~mol} \mathrm{~cm}^{-2}, 8.4 \times 10^{14}$ molecules $\left.\mathrm{cm}^{-2}\right)>$ Cys-FDCA $\left(1.1 \times 10^{-9} \mathrm{~mol} \mathrm{~cm}^{-2}, 6.6 \times 10^{14}\right.$ molecules $\left.\mathrm{cm}^{-2}\right)$. Since the maximum coverage expected of a monolayer of ferrocene is $4.5 \times 10^{-10} \mathrm{~mol} \mathrm{~cm}{ }^{-2},{ }^{14}$ the coverages obtained in this work are between 3 and 8 times higher than expected. It should however be noted that other workers have observed similar or even higher values compared to our results. For example, Gooding et al. ${ }^{14}$ observed a much higher surface coverage $\left(1.8 \pm 0.9 \times 10^{-8} \mathrm{~mol} \mathrm{~cm} \mathrm{~cm}^{-2}\right)$ for randomlydistributed ferrocenes on SWCNTs and attributed this to the existence of a three-dimensional network of redox sites. Flavel et al. ${ }^{15}$ observed a $1.14 \times 10^{-9} \mathrm{~mol} \mathrm{~cm}^{-2}$ and $9.59 \times$ $10^{-8} \mathrm{~mol} \mathrm{~cm}^{-2}$ ) for macro- and nanoscale ferrocenemethanolmodified carbon nanotube electrodes on silicon, respectively. Chambers et al. ${ }^{12}$ reported values of $\sim 4 \times 10^{14}$ molecules $\mathrm{cm}^{-2}$. It is possible that the high surface coverages obtained in our experiments could be due to the long exposure time of cysteamine to gold electrode leading to more binding sites for the ferrocenes. The high surface coverage for the SWCNT/ FMCA compared to SWCNT/FDCA suggests that the FMCA species probably coordinates more with SWCNTs via ester bonds as described above compared to its FDCA counterparts. It is known from Chidsey and co-workers ${ }^{2,36,37}$ that high concentration of ferrocene adsorbates leads to asymmetric and broad voltammograms, hence high $\Delta E_{\mathrm{p}}$ values. Thus, the higher surface coverage shown by the FMCA-based electrode (Table 1) may further explain the poor $\Delta E_{\mathrm{p}}$ and $E_{\mathrm{fwhm}}$ values of the SWCNT/FMCA compared to its SWCNT/FDCA counterpart.

Electrochemical impedance spectroscopy (EIS) is an important techniques for probing heterogeneous electron transfer (HET) kinetics, especially at gold electrodes modified with self-assembled mono- or multi-layers of redox-active or redox-silent species. ${ }^{35,38-41}$ To establish the HET kinetics in this acidic solution, EIS experiments were carried out for each of the modified electrode, as described by Creager and Wooster. ${ }^{38}$ Fig. 3a presents typical comparative Nyquist plots obtained for the four modified electrodes, biased at their approximate formal potential $(\sim 0.14 \mathrm{~V} v s . \mathrm{Ag} \mid \mathrm{AgCl})$. Interestingly, the experimental data were satisfactorily fitted with the modified Randles electrical equivalent circuit (Fig. 3b), popularly used for modelling a redox-active monolayer on an electrode surface. ${ }^{35,38}$

In the model, the $R_{\mathrm{s}}$ is the solution or electrolyte resistance, $R_{\mathrm{ct}}$ represents the electron-transfer resistance, while the true double layer capacitance $\left(C_{\mathrm{dl}}\right)$ is replaced by a constant phase element $\left(\mathrm{CPE}_{1}\right)$ and Warburg impedance $\left(Z_{\mathrm{w}}\right)$ replaced by another constant phase element $\left(\mathrm{CPE}_{2}\right.$ or capacitance of the
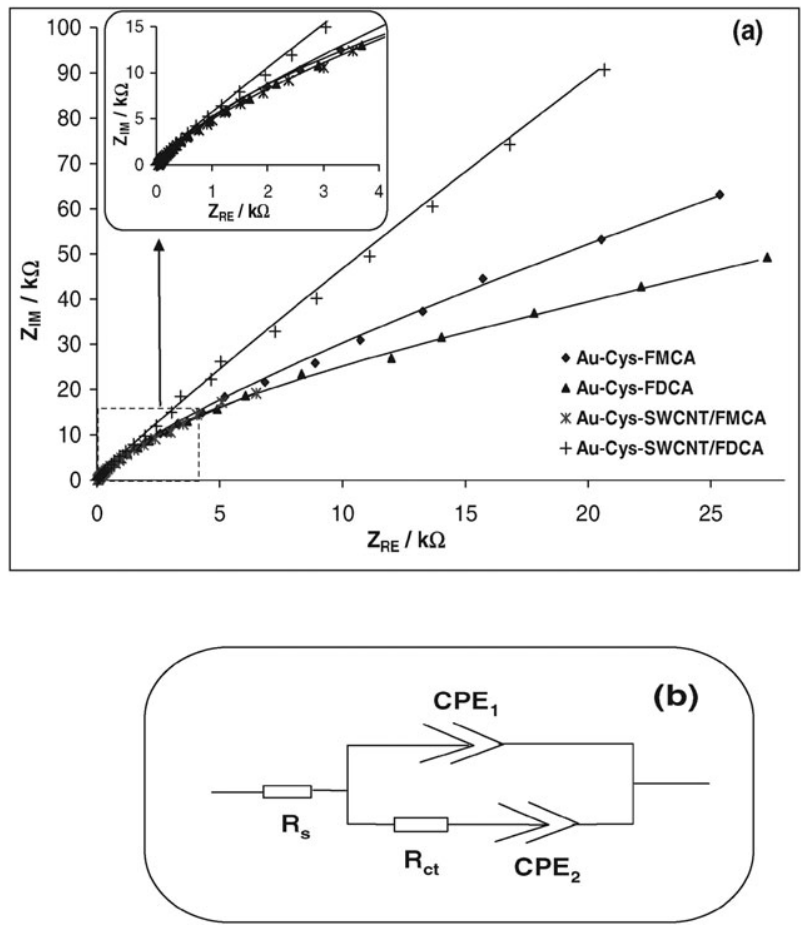

Fig. 3 Nyquist plot (a) and the (b) electrical equivalent circuit used to fit the impedance spectra of Au-Cys-FMCA, Au-Cys-FDCA, Au-CysSWCNT/FMCA and Au-Cys-SWCNT/FDCA electrodes obtained in $0.5 \mathrm{M} \mathrm{H}_{2} \mathrm{SO}_{4}$. The symbols in (a) represent the experimental data, while solid lines are the fitted curves using the modified Randles equivalent circuit (b).

adsorbed molecules). The electron transfer rate constant $\left(k_{\mathrm{et}}\right)$ of each of the electrodes was obtained from: ${ }^{35,38}$

$$
k_{\mathrm{et}}=\frac{1}{\left(2 R_{\mathrm{ct}} \mathrm{CPE}_{2}\right)}
$$

From Table 2, the $k_{\text {et }}$ value increased as follows: Au-CysFMCA $\left(\sim 12 \mathrm{~s}^{-1}\right) \approx \mathrm{Au}-\mathrm{Cys}-\mathrm{SWCNT} / \mathrm{FDCA}\left(\sim 10 \mathrm{~s}^{-1}\right)>$ Au-Cys-FDCA $\left(\sim 0.8 \mathrm{~s}^{-1}\right)>$ Au-Cys-SWCNT/FMCA $\left(\sim 0.3 \mathrm{~s}^{-1}\right)$, in close agreement with of the $\mathrm{CV}$ data listed in Table 1. It is interesting to observe how the neighbouring SWCNTs impact on the HET of the two different types of ferrocenes; SWCNTs improve the HET of ferrocene with exposed - $\mathrm{COOH}$ groups (FDCA) but decrease the HET of the ferrocene containing no pendant $-\mathrm{COOH}$ groups (FMCA).

The impedance of a CPE $\left(Z_{\mathrm{CPE}}\right)$ is defined as: ${ }^{42,43}$

$$
Z_{\mathrm{CPE}}=\frac{1}{\left[Q(j \omega)^{n}\right]}
$$


Table 2 Summary of estimated EIS parameters obtained for the modified electrodes in $0.5 \mathrm{M} \mathrm{H}_{2} \mathrm{SO}_{4}$

\begin{tabular}{|c|c|c|c|c|c|c|c|}
\hline \multirow[b]{2}{*}{ Electrodes } & \multicolumn{7}{|c|}{ Electrochemical Impedemetric parameters ${ }^{a}$} \\
\hline & $R_{\mathrm{s}} / \Omega$ & $\mathrm{CPE}_{1} / \mu \mathrm{F}$ & $n_{1}$ & $R_{\mathrm{ct}} / \mathrm{k} \Omega$ & $\mathrm{CPE}_{2} / \mu \mathrm{F}$ & $n_{2}$ & $k_{\mathrm{et}} / \mathrm{s}^{-1}$ \\
\hline Au-Cys-FMCA & $49.50(0.72)$ & $2.20(3.57)$ & $0.97(0.44)$ & $11.56(27.61)$ & $3.66(1.59)$ & $0.56(1.09)$ & 11.80 \\
\hline Au-Cys-FDCA & $40.20(0.66)$ & $5.07(1.08)$ & $0.93(0.18)$ & $76.31(6.20)$ & $8.38(2.40)$ & $0.66(3.46)$ & 0.78 \\
\hline Au-Cys-SWCNT/FMCA & $41.50(1.50)$ & $8.00(1.86)$ & $0.92(0.36)$ & $116.2(6.36)$ & $16.19(5.23)$ & $0.77(2.76)$ & 0.27 \\
\hline Au-Cys-SWCNT/FDCA & $18.90(1.16)$ & $4.32(2.81)$ & $0.94(0.71)$ & $24.16(29.22)$ & $2.16(5.02)$ & $0.66(1.27)$ & 9.56 \\
\hline
\end{tabular}

where $Q$ is the frequency-independent constant relating to the surface electroactive properties, $\omega$ is the radial frequency, the exponent $n$ arises from the slope of $\log Z v s$. $\log f$, where $f$ is the frquency (and has values $-1 \leq n \leq 1$ ). If $n=0$, the CPE behaves as a pure resistor; for $n=1, \mathrm{CPE}$ behaves as a pure capacitor; and for $n=-1$, CPE behaves as an inductor; while $n=0.5$ corresponds to the Warburg impedance $\left(Z_{\mathrm{w}}\right)$ which is associated with the domain of mass transport control arising from the diffusion of ions to and from the electrode|solution interface. In general terms, CPE arises from such factors as (i) the nature of the electrode (e.g. roughness and polycrystallinity), (ii) distribution of the relaxation times due to heterogeneities existing at the electrode/electrolyte interface, (iii) porosity and (iv) dynamic disorder associated with diffusion. ${ }^{44}$ Thus, the $n_{1}$ values in Table 2 are approximately close to 1.0 for an ideal capacitive behaviour, while the $n_{2}$ (that replaced the Warburg diffusion) are in the range between 0.56 and 0.77 , describing the porous nature of the adsorbed film on the gold electrode. The apparent electron-transfer rate constant $\left(k_{\text {app }}\right)$ values of the electrodes were obtained from eqn (1). The phase angles seen on the other Bode plots (i.e. - phase angle $(-\phi) v s . \log f$, Fig. 4a) are in the range of $75-80^{\circ}$, which are less than the $90^{\circ}$ expected of an ideal capacitive behaviour. The slopes of the Bode plots $(\log Z$ vs. $\log f$, Fig. 4b) are approximately similar (ca. -0.82 , $r^{2}=0.992$ ) at the mid frequency region, indicative of pseudocapacitive behaviour. At high frequency regions, the slopes are almost zero, indicative of resistive behaviour at these high frequency regions.

Next, we interrogated the voltammetric behaviour of the electrodes when subjected to repetitive scanning in acidic electrolyte. This experiment is necessary for establishing the electrochemical stability of these redox-active adsorbates. Fig. 5 shows typical voltammograms (1st and 20th scans of
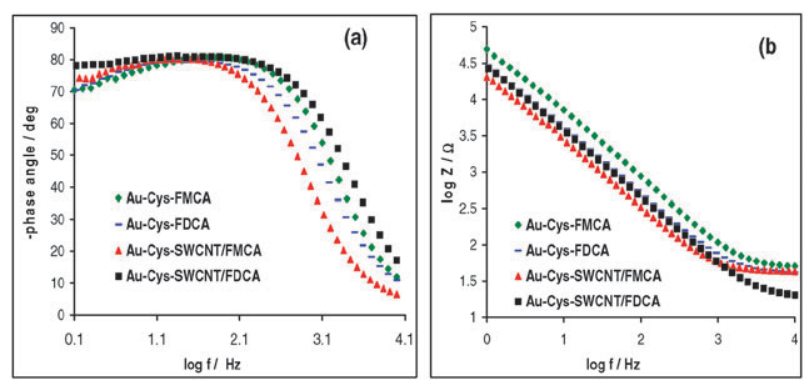

Fig. 4 Bode plots, phase angle $v s . \log f$ (a) and $\log Z v s$. $\log f(\mathrm{~b})$, of the impedance spectra of the modified electrodes in $0.5 \mathrm{M} \mathrm{H}_{2} \mathrm{SO}_{4}$. Experimental conditions are same as in Fig. 3. each electrode) obtained on repetitively scanning each electrode in the $0.5 \mathrm{M} \mathrm{H}_{2} \mathrm{SO}_{4}$ solution. For all the electrodes, we observed that the first few scans ( $c a$. 1-5 scans) remained unchanged. However, as the scan number was increased, the voltammograms became broadened (thereby increasing both the $E_{\text {fwhm }}$ and $\Delta E_{\mathrm{p}}$ values) stabilizing at about the 20th scan.

Unlike the low values of the $\Delta E_{\mathrm{p}}$ seen at the first five scans (Table 1), at the 20th scan the $\Delta E_{\mathrm{p}}$ values increased to $\sim 100 \mathrm{mV}$ for the Cys-FMCA, $>200 \mathrm{mV}$ for the Cys-FDCA, and $\sim 100 \mathrm{mV}$ for the SWCNT/FDCA. For the SWCNT/FMCA, however, there was a slight decrease from its original $95 \mathrm{mV}$ to about $80 \mathrm{mV}$ at the 20th scan. This is an interesting observation considering that such behaviour has only been observed when the concentration of ferrocene adsorbates is increased. 2,36,37 Besides, Finklea ${ }^{45}$ had demonstrated that the cause of such behavior arising from an increase in concentration of the ferrocene to be due to double-layer effects which arise from a rapid increase in surface charge during oxidation. In other words, surface charge effectively decreases the potential difference between the remaining unoxidized ferrocenes and the surface, thus requiring a high applied bias for the oxidation of these ferrocene. However, in our case, since the concentration of the ferrocene species in each electrode is the same at all scans, the assumption of the asymmetric and broadening nature of the redox peaks during repetitive scanning may probably be due to the disordering of the initial well-separated ferrocene species to a form where they now interact with one another. Simply put, during the first few scans of the
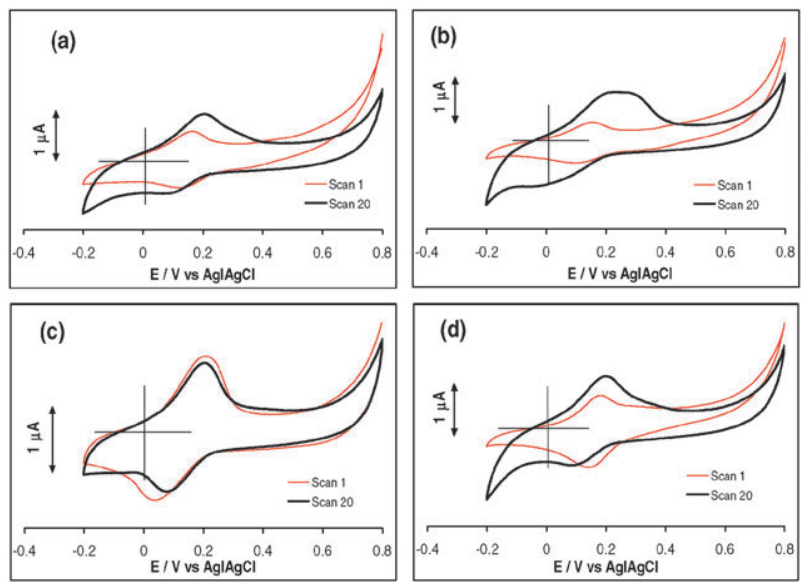

Fig. 5 Comparative cyclic voltammetric evoluions of the modified gold electrode in $0.5 \mathrm{M} \mathrm{H}_{2} \mathrm{SO}_{4}$ obtained at the 1st and the 20th scans for (a) Au-Cys-SWCNT/FDCA, (b) Au-Cys-FDCA, (c) Au-CysSWCNT/FMCA and (d) Au-Cys-FMCA. Scan rate $=25 \mathrm{mV} \mathrm{s}^{-1}$. 
ferrocene-based electrodes, the ferrocenes head groups are still well-separated and do not interact with with one another (indicated by the near-ideal $E_{\text {fwhm }}$ value, Table 1). However, as the scanning number is increased, these ferrocenes may now begin to interact with one another and/or the double layer effects ensue. Also, it is worth noting from Fig. 3 that without the SWCNTs, the $\Delta E_{\mathrm{p}}$ value is higher compared to when ferrocene is co-assembled with the SWCNTs, suggesting that SWCNTs tend to suppress this double-layer effects (for example, compare the CVs of Au-Cys-FMCA and Au-CysSWCNT/FMCA).

The existence of the ferrocene redox activity during the repetitive scanning indicates that the modified electrodes exhibited strong electrochemical stability in $0.5 \mathrm{M} \mathrm{H}_{2} \mathrm{SO}_{4}$ solution. Such stability is important for their electrochemical studies as well as their potential applications in acidic $\mathrm{pH}$ conditions. Thus, all subsequent experiments with each of the ferrocene-based electrodes were performed after 20 continuous cyclic voltammetric scanning in $0.5 \mathrm{M} \mathrm{H}_{2} \mathrm{SO}_{4}$ solution at $50 \mathrm{mV} \mathrm{s}^{-1}$.

\subsection{Hetereogeneous electron transfer dynamics in a redox probe, $\left[\mathrm{Fe}(\mathrm{CN})_{6}\right]^{4-} /\left[\left.\mathrm{Fe}(\mathrm{CN})_{6}\right|^{3-}\right.$}

Electron transport properties of the electrodes were studied in PBS solution containing the outer-sphere redox probe, $\left[\mathrm{Fe}(\mathrm{CN})_{6}\right]^{4-} /\left[\mathrm{Fe}(\mathrm{CN})_{6}\right]^{3-}(\mathrm{pH} 7.2)$. Typical comparative CVs are exemplified in Fig. 6. The $\Delta E_{\mathrm{p}}$ values for all the electrodes are essentially the same $(\sim 110 \mathrm{mV})$ with the same equilibrium potential $\left(E_{1 / 2} \approx 100 \mathrm{mV}\right)$. Since electrochemical impedance spectroscopy (EIS) provides a more detailed description of an electrochemical system ${ }^{46}$ than cyclic voltammetry does, EIS was used to follow the electron transfer kinetics occurring at these electrodes.

The EIS measurements were performed at the formal potential $\left(E_{1 / 2} \approx 100 \mathrm{mV}\right)$. Fig. 7 shows examples of the Nyquist plots obtained for all the electrodes in the outer-sphere redox probe, $\left[\mathrm{Fe}(\mathrm{CN})_{6}\right]^{4-} /\left[\mathrm{Fe}(\mathrm{CN})_{6}\right]^{3-}$ solution $(\mathrm{pH} \mathrm{7.2)}$.

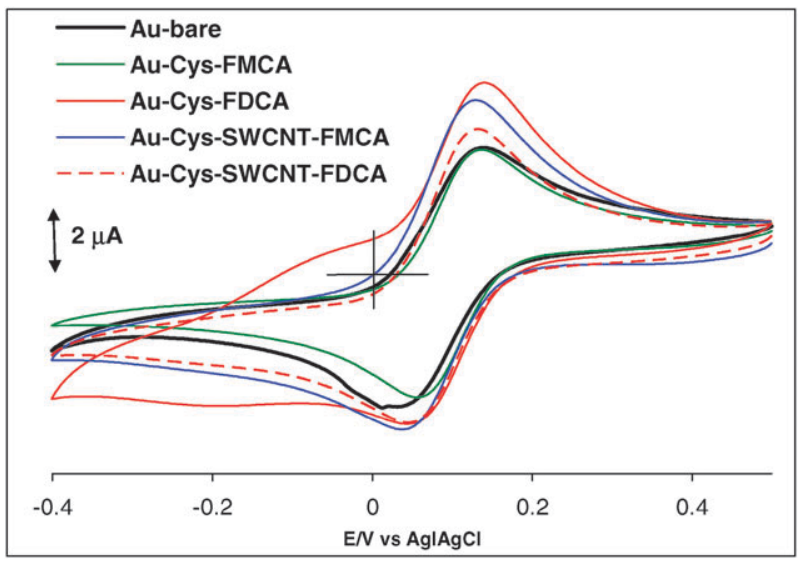

Fig. 6 Comparative cyclic voltammetric evoluions of the bare and modified gold electrodes obtained in $0.1 \mathrm{M}\left[\mathrm{Fe}(\mathrm{CN})_{6}\right]^{4-} /\left[\mathrm{Fe}(\mathrm{CN})_{6}\right]^{3-}$ (PBS, pH 7.2); bare Au, Au-Cys-FDCA, Au-Cys-FMCA, Au-Cys-SWCNT/FDCA and Au-Cys-SWCNT/FMCA. Scan rate $=$ $25 \mathrm{mV} \mathrm{s}^{-1}$.
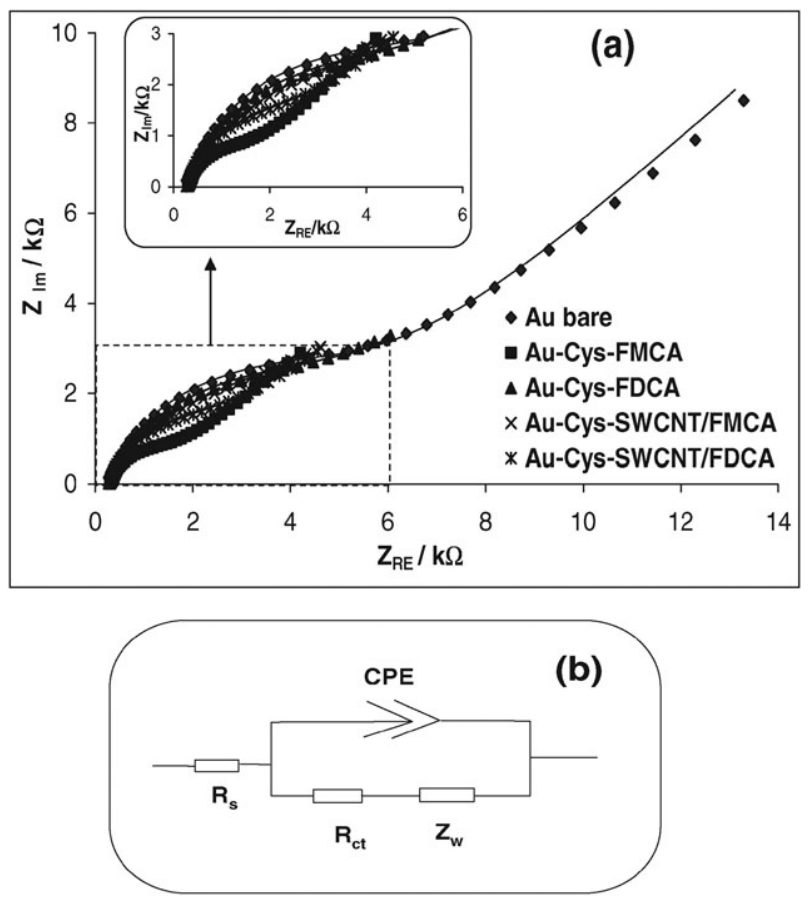

Fig. 7 Nyquist plot (a) and the electrical equivalent circuit (b) used to fit the impedance spectra of bare Au, Au-Cys-FMCA, Au-Cys-FDCA, Au-Cys-SWCNT/FMCA and Au-Cys-SWCNT/FDCA obtained in $0.1 \mathrm{M}\left[\mathrm{Fe}(\mathrm{CN})_{6}\right]^{4-} /\left[\mathrm{Fe}(\mathrm{CN})_{6}\right]^{3-}(\mathrm{PBS}, \mathrm{pH} 7.2)$. The symbols in (a) represent the experimental data, while solid lines are the fitted curves using the modified Randles equivalent circuit (b).

The EIS data were satisfactorily fitted with the modified Randles equivalent circuit model (Fig. 7b), judged by the relative $\%$ errors (Table 2 ) wherein the true capacitance is replaced by the constant phase element (CPE). In this model the $R_{\mathrm{s}}$ is the solution/electrolyte resistance, $R_{\mathrm{ct}}$ represents the electron-transfer resistance, while the $Z_{\mathrm{w}}$ is the Warburg impedance. The apparent electron transfer rate constant $\left(k_{\text {app }}\right)$ of each of the electrodes was obtained from eqn (4):

$$
k_{\mathrm{app}}=\frac{R T}{n^{2} F^{2} A R_{\mathrm{ct}} C}
$$

where $n$ is the number of electrons transferred (1), $F$ is the Faraday constant, $R$ is the ideal gas constant, $T$ is the Kelvin temperature, $A$ is the experimentally-determined area of the electrode, the $R_{\mathrm{ct}}$ value is obtained from the fitted Nyquist plots, $C$ is the concentration of the $\left[\mathrm{Fe}(\mathrm{CN})_{6}\right]^{3-}$ (in $\mathrm{mol} \mathrm{cm}^{-3}$, the concentration of $\left[\mathrm{Fe}(\mathrm{CN})_{6}\right]^{3-}$ and $\left[\mathrm{Fe}(\mathrm{CN})_{6}\right]^{4-}$ are equal). From Table 3 , the $k_{\text {app }}$ values increase as follows: Au-Cys-FMCA > Au-Cys-SWCNT/FDCA > Au-Cys-SWCNT/FMCA $\approx$ Au-Cys-FDCA $>$ bare Au. Within the limits of experimental errors, the trend in the electron transport kinetics seen in the redox probe $\left(\left[\mathrm{Fe}(\mathrm{CN})_{6}\right]^{3-} /\left[\mathrm{Fe}(\mathrm{CN})_{6}\right]^{4-}\right.$ solution is somewhat comparable with that observed with the $\mathrm{H}_{2} \mathrm{SO}_{4}$ solution. However, we should not expect them to necessarily follow the same trend. This is because, first, the experiments were performed at different electrolyte conditions and, second, unlike the experiment in the $\mathrm{H}_{2} \mathrm{SO}_{4}$ which provides insight into the redox processes $\left(\mathrm{Fe}^{3+} / \mathrm{Fe}^{2+}\right)$ of the electrode-confined ferrocene 

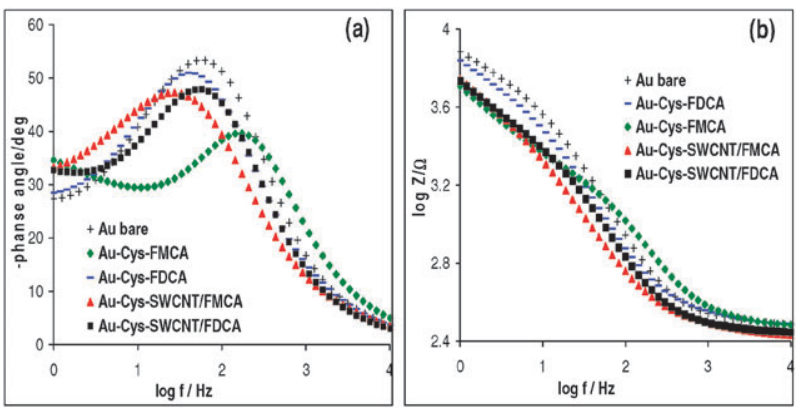

Fig. 8 Bode plots, (a) phase angle vs. $\log f$ and (b) $\log Z v s . \log f$ of the impedance spectra of the modified electrodes in redox probe $\left(\left[\mathrm{Fe}(\mathrm{CN})_{6}\right]^{4-} /\left[\mathrm{Fe}(\mathrm{CN})_{6}\right]^{3-}\right.$ ) PBS solution ( $\mathrm{pH}$ 7.2). Experimental conditions are same as in Fig. 7.

species, the experiment with the $\left[\mathrm{Fe}(\mathrm{CN})_{6}\right]^{3-} /\left[\mathrm{Fe}(\mathrm{CN})_{6}\right]^{4-}$ solution essentially interrogates the extent to which the immobilized ferrocene species permit the permeation of the redox probe and/or enhance the faradaic response of the $\left[\mathrm{Fe}(\mathrm{CN})_{6}\right]^{3-}$ and $\left[\mathrm{Fe}(\mathrm{CN})_{6}\right]^{4-}$ species. The $n$ values (Table 3) are in the range 0.76 and 0.86 , indicative of pseudocapacitive behaviour. From the Bode plots (Fig. 8), the values of the slopes of the $\log Z v s . \log f$ plot (ca. -0.57) as well as the phase angles (less than $90^{\circ}$ ) confirm the pseudocapacitive behaviour. Notice from the Bode plot (Fig. 8a) that the peak of the Au-Cys-FMCA occurred at a higher frequency $(\sim 200 \mathrm{~Hz})$ than the others which occurred at frequencies $<100 \mathrm{~Hz}$. This indicates that the electrochemical reaction rates is faster with $\mathrm{Au}$-Cys-FMCA, as $f$ usually represents the time constants of an electrochemical reaction.

\subsection{Electrocatalytic detection of thiocyanate}

Having established that the neighbouring SWCNTs impact on the HET of the ferrocene molecular assemblies, we thought it was necessary to establish the extent to which these SWCNTs could impact on the electrocatalytic behaviour of the ferrocenes. For this study, we chose thiocyanate $\left(\mathrm{SCN}^{-}\right)$as a model analyte. Fig. 9 shows the comparative square wave voltammetric (SWV) evolutions obtained at constant concentration $(1 \mathrm{mM})$ of $\mathrm{SCN}^{-}$at the various electrodes in PBS (pH 4.8). This $\mathrm{pH}$ condition was chosen for this experiment as it is well known to enhance the detection of thiocyanate. ${ }^{47-49}$

The catalytic behaviour (in terms of onset potential) follows this trend: bare $\mathrm{Au}(0.64 \mathrm{~V})>\mathrm{Au}-\mathrm{Cys}-\mathrm{SWCNT}(0.62 \mathrm{~V})>$ Au-Cys-FMCA $\approx$ Au-Cys-FDCA $(0.48 \mathrm{~V})>$ Au-Cys-SWCNT/ FMCA $(0.50$ V) $>$ Au-Cys-SWCNT/FDCA (0.42 V). Au-Cys-SWCNT/FDCA and Au-Cys-SWCNT/FMCA gave

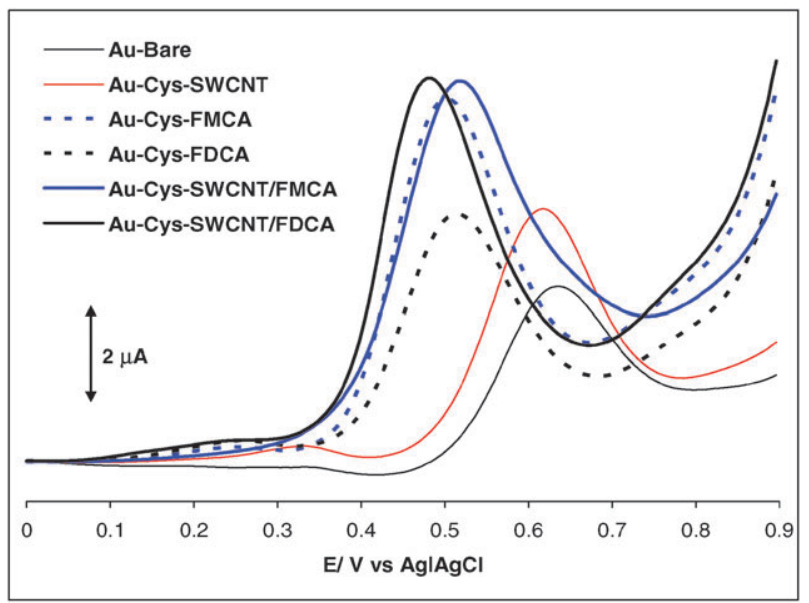

Fig. 9 Comparative square wave voltammograms of the bare gold and modified gold electrodes obtained in PBS solution ( $\mathrm{pH}$ 4.7) containing $1 \mathrm{mM} \mathrm{SCN}^{-}$.

the highest current response with less positive onset potential (0.3 V) compared to other electrodes. However, Au-Cys-SWCNT/ FDCA recorded the least peak potential for the oxidation of $\mathrm{SCN}^{-}$at $0.48 \mathrm{~V}$, possibly due to the repulsive interaction between the negatively charged $\mathrm{SCN}^{-}$and high number of surface $-\mathrm{COOH}$ species at the FDCA. Second, the ferrocenebased electrode without the SWCNTs (i.e. Au-Cys-FDCA and Au-Cys-FMCA) exhibited a more positive onset potential $(\sim 0.35 \mathrm{~V})$ for the oxidation of $\mathrm{SCN}^{-}$than the ones containing SWCNTs (Au-Cys-SWCNT/FDCA and Au-Cys-SWCNT/ FMCA) at $0.3 \mathrm{~V}$. This improved response towards the detection of $\mathrm{SCN}^{-}$species is due the combined synergistic activities of good electrocatalysts (FDCA or FCA) and the efficient electronic conducting nanowires (SWCNTs). This finding is quite remarkable especially when compared to data previously obtained at the iron (II) phthalocyanine (FePc) and SWCNTiron (II) octa(hydroethylthio) phthalocyanine (FeOHETPc) SAM modified electrodes where the oxidation of $\mathrm{SCN}^{-}$ occurred at peak potentials $\geq 0.60 \mathrm{~V} .^{48,49}$ Also, the current responses recorded in this present work for the Au-CysSWCNT/FDCA and Au-Cys-SWCNT/FMCA for the same concentration of $\mathrm{SCN}^{-}(1 \mathrm{mM})$ is approximately twice that reported for the FeOHETPc and FePc-SAM modified electrodes. ${ }^{48,49}$

Chronoamperometric detection of $\mathrm{SCN}^{-}$at the Au-CysSWCNT/FDCA (Fig. 10) gave a higher sensitivity of $\sim 7.5 \times 10^{-3} \mathrm{AM}^{-1}$ compared to the $4.2 \times 10^{-3} \mathrm{AM}^{-1}$ obtained before. ${ }^{20}$ The detection limit was of $\sim 1 \mu \mathrm{M}$. We

Table 3 Summary of estimated EIS parameters obtained in $0.1 \mathrm{M}\left[\mathrm{Fe}(\mathrm{CN})_{6}\right]^{4-} /\left[\mathrm{Fe}(\mathrm{CN})_{6}\right]^{3-}(\mathrm{PBS}, \mathrm{pH} 7.2)$

\begin{tabular}{|c|c|c|c|c|c|c|}
\hline \multirow[b]{2}{*}{ Electrodes } & \multicolumn{6}{|c|}{ Electrochemical impedemetric parameters ${ }^{a}$} \\
\hline & $R_{\mathrm{S}} / \Omega$ & $\mathrm{CPE} / \mu \mathrm{F}$ & $n$ & $R_{\mathrm{ct}} / \mathrm{k} \Omega$ & $Z_{\mathrm{W}} / \mu \Omega$ & $10^{3} k_{\mathrm{app}} / \mathrm{cm} \mathrm{s}^{-1}$ \\
\hline $\mathrm{Au}$ & $305.81(0.43)$ & $5.32(2.02)$ & $0.86(0.37)$ & $5.12(1.15)$ & $104.0(0.90)$ & $1.93 \pm 0.02$ \\
\hline Au-Cys-FMCA & $300.90(0.40)$ & $0.44(4.16)$ & $0.86(0.58)$ & $1.41(1.64)$ & $98.3(0.68)$ & $6.98 \pm 0.11$ \\
\hline $\mathrm{Au}-\mathrm{Cys}-\mathrm{FDCA}$ & $310.00(0.63)$ & $0.63(5.56)$ & $0.82(0.69)$ & $4.93(3.03)$ & $118.7(4.52)$ & $2.00 \pm 0.06$ \\
\hline Au-Cys-SWCNT/FMCA & $271.70(0.53)$ & $0.52(5.59)$ & $0.76(0.68)$ & $4.65(3.87)$ & $126.6(4.67)$ & $2.12 \pm 0.08$ \\
\hline Au-Cys-SWCNT/FDCA & $280.10(0.33)$ & $0.98(3.22)$ & $0.86(0.45)$ & $2.58(1.83)$ & $107.6(1.28)$ & $3.82 \pm 0.07$ \\
\hline
\end{tabular}




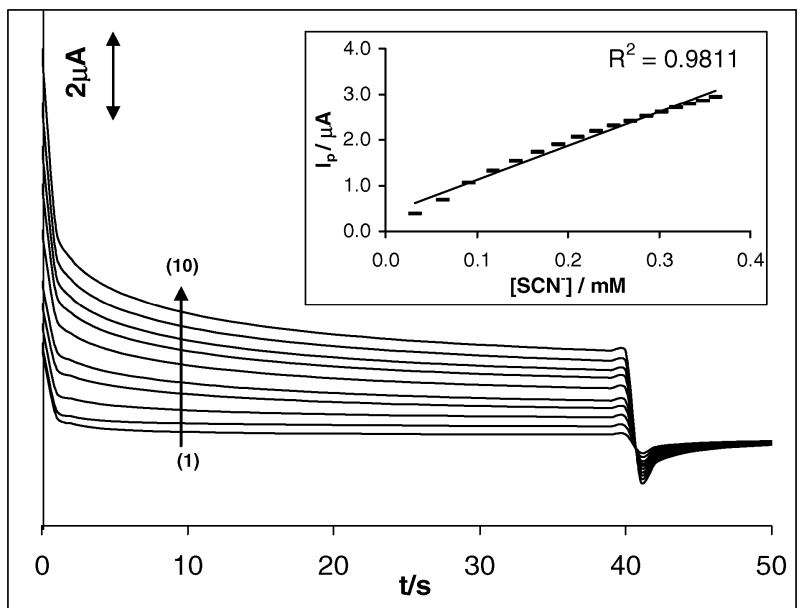

Fig. 10 Typical double potential step chronoamperometric transients at Au-Cys-SWCNT-FDCA in PBS solution ( $\mathrm{pH}$ 4.7) following the addition of thiocyanate (numbers 1-10 correspond to the increasing concentrations). The potential was stepped at +0.45 and $+0.20 \mathrm{~V}$. Inset is the plot of the chronoamperometric current vs. $\left[\mathrm{SCN}^{-}\right]$.

also tested the suitability of the ITO-nanoAu-Cys-SWCNT/ FDCA for a possible application as a disposable, one-shot electrode system for a quick chronoamperometric detection of $\mathrm{SCN}^{-}$(not shown). The ITO-nanoAu used for this experiment was fabricated using the mediated growth mechanism as reported in a previous communication. ${ }^{50}$ With this electrode, we also recorded chronoamperometric sensitivity of $7.3 \times 10^{-3}$ and a limit of detection of $\sim 13 \mathrm{nM}$ for the $\mathrm{SCN}^{-}$, comparable to the data obtained at the modified bulk gold electrode.

\section{Conclusions}

This study has for the first time interrogated the electrochemistry of electron transfer dynamics of ferrocene-terminated self-assembled monolayers (SAMs), co-adsorbed with SWCNTs on a gold electrode. Factors influencing electron transport within organized molecular assemblies are crucial for the potential applications of such platforms in many areas such as in molecular electronics, chemical and biological sensings. The important findings in this work should be emphasized. First, the neighbouring SWCNTs in the ferrocene molecular assemblies exert distinct impacts on the global electron transport and electrocatalytic behaviour of the ferrocenes. Second, that the presence of SWCNTs in the ferrocene assembly synergistically enhances the electrocatalytic detection of thiocyanate compared to the ferrocene or SWCNTs alone. In a nutshell, this study has provided some useful physical insights into the impact of local SWCNTs microenvironment surrounding a redox-active and electrocatalytic molecule (not only ferrocene but other related organometallic species) on the dynamics of electron transport between solution species and electrode. We envisage that these insights have provided some thoughts on the factors that must be considered when designing molecular-scale electronics or electrocatalytic devices that employ CNT and ferrocenes (or related species).

\section{Acknowledgements}

We thank the National research Foundation (NRF, South Africa) and CSIR for their financial support. DN thanks NRF for PhD bursary. JP thanks MinTeK and NRF for PhD bursaries.

\section{References}

1 J. A. Pelesko, Self-assebly: The science of things that put themselves together, Chapman \& Hall/CRC, Boca Raton, FL, 2007, ch. 1, p. 1.

2 C. E. D Chidsey, C. R. Bertozzi, T. M. Putvinski, and A. M. Mujsce, J. Am. Chem. Soc., 1990, 112, 4301.

3 K. Weber, L. Hockett and S. Creager, J. Phys. Chem. B, 1997, 101, 8286 .

4 J. J. Sumner and S. E. Creager, J. Phys. Chem. B, 2001, 105, 8739.

5 C. Hortholary and C. Crouchet, C. R. Chim., 2008, 11, 702.

6 J. P. Collman, N. K. Devaraj and C. E. D. Chidsey, Langmuir, 2004, 20, 1051.

7 T. Auletta, F. C. J. M van Veggel and D. N. Reinhoudt, Langmuir, 2002, 18, 1288.

8 S. Ye, T. Haba, Y. Sato, K. Shimazu and K. Uosaki, Phys. Chem. Chem. Phys., 1999, 1, 3653.

9 A. M. Napper, H. Liu and D. H. Waldeck, J. Phys. Chem. B, 2001, 105, 7699.

10 T. Kondo, T. Kanai and K. Uosaki, Langmuir, 2001, 17, 6317.

11 S.-K. Oh, L. A. Baker and R. M. Crooks, Langmuir, 2002, 18, 6981 .

12 R. C. Chambers, C. E. Inman and J. E. Hutchinson, Langmuir, 2005, 21, 4615.

13 J. J. Gooding, Electrochim. Acta, 2005, 50, 3049.

14 J. J. Gooding, A. Chou, J. Liu, D. Losic, J. G. Shapter and D. B. Hibbert, Electrochem. Commun., 2007, 9, 1677.

15 B. S. Flavel, J. Yu, A. V. Ellis and J. G. Shapter, Electrochim. Acta, 2009, 54, 3191.

16 P. M. Maliszewski and H. E. Bass, J. Appl. Physiol., 1955, 8, 289.

17 Z. Guien, L. Bin, F. Jing and F. Suling, Talanta, 1997, 44, 1141.

18 H. A. Zamani, F. Malekadegan and M. R. Ganjali, Anal. Chim. Acta, 2006, 555, 336.

19 J. Liu, A. G. Rinzler, H. Dai, J. H. Hanfer, R. K. Bradley, P. J. Boul, A. Lu, T. Iverson, K. Shelimov, C. B. Huffman, F. R. Macias, Y. S. Shon, T. R. Lee, D. T. Colbert and R. E. Smalley, Science, 1998, 280, 1253.

20 D. Nkosi and K. I. Ozoemena, Electrochim. Acta, 2008, 53, 2782.

21 B. O. Agboola and K. I. Ozoemena, Phys. Chem. Chem. Phys., 2008, 10, 2399.

22 R. G. Compton and C. E. Banks, Understanding Voltammetry, World Scientific Publishing Company, London, 2007.

23 A. J. Bard and L. R. Faulkner, Electrochemical Methods, John Wiley and Sons, New York, 2001.

24 J. Yu, J. G. Shapter, J. S. Quinton, M. R. Johnston and D. A. Beattie, Phys. Chem. Chem. Phys., 2007, 9, 510.

25 J. J. Gooding, R. Wibowo, J. Liu, W. Yang, D. Losic, S. Orbons, F. J. Meams, J. G. Shapter and D. B. Hibbert, J. Am. Chem. Soc., 2003, 125, 9006.

26 K. I. Ozoemena, T. Nyokong, D. Nkosi, I. Chambrier and M. J. Cook, Electrochim. Acta, 2007, 52, 4132.

27 A. Guiseppi-Elie, A. R. Abdur Rahman and N. K. Shukla, Electrochim. Acta, 2008, DOI: 10.1016/j.electacta.2008.12.043.

28 K. Ozoemena and T. Nyokong, Electrochim. Acta, 2002, 47, 4035.

29 K. I. Ozoemena, T. Nyokong and P. Westbroek, Electroanalysis, 2003, 15, 1762.

30 H. O. Finklea, in Electroanalytical Chemistry, ed. A. J. Bard and I. Rubinstein, Marcel Dekker, New York, 1996, vol. 19, p. 109.

31 H. O. Finklea, J. Am. Chem. Soc., 1992, 114, 3173.

32 H. O. Finklea, M. S. Ravenscroft and D. A. Snider, Langmuir, 1993, 9, 223.

33 G. K. Rowe, M. T. Carter, J. N. Richardson and R. W. Murray, Langmuir, 1995, 11, 1797.

34 S. Chen and R. W. Murray, J. Phys. Chem. B, 1999, 103, 9996.

35 S. Chen, J. Phys. Chem. B, 2000, 104, 663.

36 C. E. D. Chidsey, Science, 1991, 251, 919. 
37 R. W. Murray, in Electroanalytical Chemistry, ed. A. J. Bard, Marcel Dekker, New York, 1984, vol. 13, p. 191.

38 S. E. Creager and T. T. Wooster, Anal. Chem., 1998, 70, 4257.

39 L. V. Protsailo and W. R. Fawcett, Electrochim. Acta, 2000, 45, 3497.

40 M. I. Prodromidis, Electrochim. Acta, 2009, DOI: 10.1016/j.electacta.2009.01.081.

41 N. S. Mathebula, J. Pillay, G. Toschi, J. A. Verschoor and K. I. Ozoemena, Chem. Commun., 2009, 3345.

42 E. Barsoukov and J. R. Macdonald, Impedance Spectroscopy: Theory Experiment, and Applications, Wiley, Hoboken, New Jersey, 2nd edn, 2005, ch. 1-4.

43 M. E. Orazem and B. Tribollet, Electrochemical Impedance Spectroscopy, John Wiley \& Sons Inc., Hoboken, NJ, 2008, ch. 13.
44 V. Ganesh, S. Pitchumani and V. Lakshminarayanan, J. Power Sources, 2006, 158, 1523.

45 H. O. Finklea, in Electroanalytical Chemistry, ed. A. J. Bard, Marcel Dekker, New York, 1996, vol. 19, p. 109.

46 B.-Y. Chang, S.-Y. Hong, J.-S. Yoo and S.-M. Park, J. Phys. Chem. B, 2006, 110, 19385.

47 S. Adak, A. Mazumdar and R. K. Banerjee, J. Biol. Chem., 1997, 272, 11049.

48 D. Nkosi and K. I. Ozoemena, J. Electroanal. Chem., 2008, 621, 304.

49 K. I. Ozoemena and T. Nyokong, J. Electroanal. Chem., 2005, 579, 283.

50 J. Zhang, M. Kambayashi and M. Oyama, Electrochem. Commun., $2004,6,683$. 